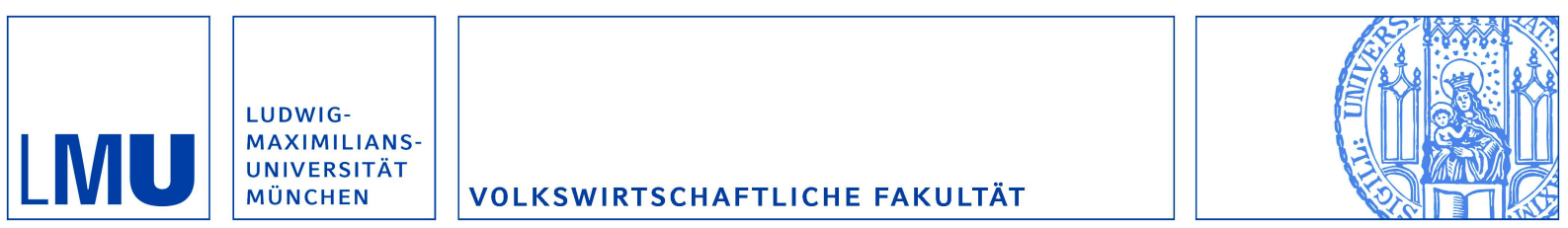

Bucovetsky, Sam und Haufler, Andreas:

Tax competition when firms choose their organizational form: Should tax loopholes for multinationals be closed?

Munich Discussion Paper No. 2005-23

Department of Economics

University of Munich

Volkswirtschaftliche Fakultät

Ludwig-Maximilians-Universität München

Online at https://doi.org/10.5282/ubm/epub.729 


\title{
Tax competition when firms choose their organizational form: Should tax loopholes for multinationals be closed? *
}

\author{
Sam Bucovetsky \\ York University, Toronto
}

\author{
Andreas Haufler \\ University of Munich
}

November 2005

\begin{abstract}
We analyze a sequential game between two symmetric countries when firms can invest in a multinational structure that confers tax savings. Governments are able to commit to long-run tax discrimination policies before firms' decisions are made and before statutory capital tax rates are chosen non-cooperatively. Whether a coordinated reduction in the tax preferences granted to mobile firms is beneficial or harmful for the competing countries depends critically on the elasticity with which the firms' organizational structure responds to tax discrimination incentives. The model can be applied to recent policy initiatives that aim at a ban on preferential tax regimes and at reducing the profit shifting opportunities for multinational firms.
\end{abstract}

Keywords: tax competition, multinational firms, preferential treatment JEL-Classification: H73, F23

*Paper presented at conferences and seminars in Bonn, Hamilton, Innsbruck, Munich and Tübingen. We thank seminar participants, in particular Marcel Gérard, Eckhard Janeba, Wilhelm Kohler, Gordon Myers and Wolfgang Peters for helpful comments, and Michael Smart for discussions about his own earlier work (joint with Qing Hong). Haufler gratefully acknowledges the hospitality of the University of York, where this research was started, and financial support from the German Research Foundation (grant no. HA 3195/1-2). 


\section{Introduction}

The issue of why firms choose a multinational structure has received much attention in the modern theory of international trade. According to this theory, savings in transportation costs and tariff-jumping arguments are among the core reasons for firms investing in more than a single country (Horstmann and Markusen, 1992). Tax savings, on the other hand, have so far played hardly any role in this literature. This is surprising, because $70 \%$ of FDI inflows and more than $90 \%$ of FDI outflows occur between the developed countries (Markusen, 2002, Table 1.2) which are characterized, on average, by high corporate taxes, but relatively low tariffs and transportation costs. ${ }^{1}$ There is by now substantial empirical evidence that multinational firms are able to significantly reduce their corporate tax burden by transfer pricing and other profit shifting strategies (Hines, 1999; Bartelsman and Beetsma, 2003). Moreover, a rising share of FDI occurs in knowledge-based industries where a large part of earnings consists of royalties and license fees that can easily be shifted internationally. ${ }^{2}$ While precise quantifications remain difficult, these tax savings are arguably at least as important from the perspective of multinational firms as the reduction of transportation costs or tariffs. Nevertheless, the extensive literature on taxation and foreign direct investment (see Gresik, 2001 for a survey) has so far not considered taxes as a potential cause for the choice of a multinational form, but has instead focussed almost exclusively on the consequences for tax policy of the existence of multinational firms. ${ }^{3}$

In this paper we present a model where firms endogenously choose a national or a multinational form, in response to the tax advantages accorded to a multinational status. These tax advantages may come in one of several forms. In Europe, for exam-

\footnotetext{
${ }^{1}$ Using revenue collections as an indicator, tariff revenue was only about $10 \%$ of corporate tax revenue in the United States in 2003 (\$21 billion vs. $\$ 200$ billion). In the European Union, the share of tariff collections over corporate tax revenue is even lower, due to the high volume of tariff-free intra-European trade. See OECD (2005).

${ }^{2}$ As an example, Microsoft has moved some of its R\&D operations to a subsidiary in Dublin, allowing the company to channel a disproportionate share of its profits from European sales to lowtax Ireland (12.5\% corporation tax). See Wall Street Journal, November 7, 2005.

${ }^{3}$ One exception is Janeba (2000), who analyzes the incentives for a monopolist to install capacities in each of two countries, in order to induce tax competition between them.
} 
ple, governments increasingly grant special tax preferences to multinational enterprises (MNEs) that are not extended to domestic firms. The EU's Primarolo Report (1999) lists a total of 66 examples of discriminatory tax preferences in favour of MNEs. A typical case are Belgium's special tax rules for large, foreign-based corporations that establish a coordination center in the country. Under this law, the normal statutory tax rate is applied to a very narrow 'notional' tax base, leading to effective tax rates that are close to zero for most of the benefitting firms (Primarolo Report, 1999, A 001). While special tax laws favouring MNEs are a particularly visible kind of tax discrimination, they are not the only one. A weak enforcement of transfer pricing rules equally grants MNEs a tax advantage over domestic firms, and thus acts as a discriminatory device. ${ }^{4}$ The importance of transfer pricing is well-documented for the United States. Swenson (2001) finds, for example, that tax reforms and the associated tariff changes led to product-specific changes in the reported values of U.S. imports from five OECD countries, which systematically reduced the tax and tariff payments by US multinational firms. Similarly, Clausing (2003) analyzes US intra-firm trade prices and finds direct evidence of transfer pricing behavior: a lower corporate tax rate abroad is associated with lower export prices from the U.S. and higher import prices into the U.S., other things being equal.

These examples demonstrate that discriminatory tax reductions in favour of mobile, multinational firms have become widespread. Moreover, tax discrimination can be actively influenced or controlled by national governments, and can therefore itself be viewed as a strategic policy variable. Therefore, a central policy question in current international tax relations has been whether this type of discrimination is collectively desirable or self-defeating in a world where countries remains free to set capital tax rates independently and a growing share of trade is carried out by MNEs.

In the political debate, the current consensus in both the OECD (1998) and the European Union seems to be that tax discrimination in favour of mobile firms is both 'unfair' and 'harmful'. The EU has adopted a Code of Conduct for business taxation (Euro-

\footnotetext{
${ }^{4}$ Bartelsman and Beetsma (2003, Table 1) give details - based on information collected by Ernst \& Young - on the formal enforcement of transfer pricing rules in 16 OECD countries. This comparison documents substantial international differences in the enforcement of transfer pricing rules and their econometric results indicate that a stricter control of these rules does indeed reduce profit shifting.
} 
pean Communities, 1998) under which member states have committed themselves to phase out existing tax preferences that either discriminate in favour of non-residents, or are extended to firms with no real economic activity in the country. Moreover, one of the main motivations behind the current EU initiative to tax multinationals under some form of formula allocation, rather than the current separate accounting system (European Commission, 2001) is to reduce profit shifting activities. Therefore, this coordination measure also has an important element of enforcing non-discriminatory corporate tax policies (Gérard, 2005). Similar policies have long been enacted in the United States and Canada, where different allocation formulas are used as a means to keep firms operating in different sub-national jurisdictions from shifting profits into low-tax states or provinces. ${ }^{5}$

From a theoretical perspective, it is by no means obvious, however, that discriminatory tax policies are harmful in a world where national or sub-national jurisdictions are free to choose corporate tax rates independently. Instead, tax rate competition may well be intensified when the possibility to tax-discriminate between internationally mobile and immobile firms is reduced.

To capture the central features of the resulting interaction between countries and firms, two model elements are important in our view. The first is the long-term nature of most tax concessions granted to MNEs, which are changed far less frequently than statutory tax rates. This observation applies to both the formal enforcement of transfer pricing rules, codified in national tax laws, ${ }^{6}$ and to many of the special tax preference schemes that explicitly aim at organizational adjustments within the tax-favoured multinational group. In the example of the Belgian coordination centers mentioned above, the tax preferences implied by the narrow tax base have been in effect continuously since 1983 . Given this country's long-term commitment to maintain its tax preference, a large number of multinational groups have been attracted to Belgium, despite the uncertainty about the development of statutory tax rates, which were changed five times since the

\footnotetext{
${ }^{5}$ A study by Mintz and Smart (2004) confirms that formula allocation reduces profit-shifting opportunities. They find for a sample of Canadian firms that the elasticity of taxable income with respect to tax rates is about twice as high for affiliated firms that are taxed under separate accounting, as compared to firms that are subject to formula allocation.

${ }^{6}$ Bartelsman and Beetsma (2003, Table 1) show that among the 11 OECD countries in their sample which do have explicit transfer pricing rules, only four have changed these rules during the 1990s.
} 
beginning of the preferential tax rule. ${ }^{7}$ The second model element, which has already been mentioned above, is that long-term tax concessions offer an incentive for firms to invest in a multinational structure, in order to benefit from these tax advantages.

In this paper we set up a model that incorporates these two elements and analyze the effects that the firms' endogenous choice of organizational form has on optimal corporate tax policy. Specifically, we model a sequential game between two symmetric countries in which governments decide in a first stage on the degree of tax preferences granted to internationally mobile firms. Firms respond to these tax preferences by deciding on whether to make a fixed investment to establish a subsidiary in another country, in order to qualify for these preferences. In the final stage of the game, governments compete for mobile capital by means of statutory corporate tax rates. The central question underlying the analysis is whether a coordinated reduction in the tax preferences granted to mobile firms is in the interest of the competing countries, given that tax rates in the final stage remain to be chosen non-cooperatively.

Our analysis relates to two different strands in the literature. A first group of papers explicitly compares inter-jurisdictional tax competition under discriminatory vs. nondiscriminatory tax regimes. Janeba and Peters (1999) show that a mutual agreement to refrain from tax discrimination is Pareto improving in a setting where two countries compete for a tax base that is perfectly mobile internationally, but at the same time are able to tax a completely inelastic domestic tax base. Keen (2001), in contrast, reaches the opposite conclusion in a model where both tax bases are internationally mobile, albeit to a different degree, and the aggregate size of each tax base is fixed. Janeba and Smart (2003) generalize Keen's model and provide a synthesis of the conditions under which a preferential tax treatment of the more mobile base is beneficial or harmful for the competing countries. Finally, Haupt and Peters (2005) show that the policy case for a ban on preferential tax regimes is strengthened when investors have a 'home bias'. All these contributions model tax discrimination as a single-stage game and assume that capital tax bases differ exogenously in the degree of international mobility. A second strand in the literature focuses on the strategic use of tax enforcement policies. Cremer and Gahvari (2000) analyze the implications of tax evasion for fiscal competi-

\footnotetext{
${ }^{7}$ See Weichenrieder (1996) for a detailed account of the response of German firms to this and other special tax schemes in the EU.
} 
tion in a federal economy. Their benchmark result establishes that competing countries will choose inefficiently low tax and audit rates in the non-cooperative equilibrium. Peralta, Wauthy and van Ypersele (2003) analyse a two-stage game between asymmetric countries which compete for the profits of a single multinational firm by means of the corporation tax rate and a tax enforcement variable. In their analysis, tax enforcement is used as a strategic instrument to influence the rival country's subsequent choice of tax rate. Finally, a direct precursor to our work is Hong and Smart (2005). They consider a general equilibrium model of a single small open economy which chooses both its statutory tax rate and the degree of tax sheltering given to multinationals. A core result of their analysis is that an increase in income shifting allows the government of the small country to increase its tax rate. None of these papers, however, endogenizes the decision of firms to invest in a multinational organizational form.

Our analysis yields the following results. When the firms' choice of organizational form responds inelastically to tax advantages, then countries will choose a high level of tax preferences in the first stage of the game, and set the statutory tax rate on immobile firms at the maximum possible level in the last. In this regime, the optimal coordinated policy is indeed to reduce the number of tax loopholes for multinationals. If, however, the response of firms' organizational form to tax preferences is elastic, then non-cooperative policies will consist of a moderate level of tax discrimination chosen in the first stage of the game, and an interior level of the statutory tax rate in the last. A coordinated policy should then increase, rather than reduce, the degree of tax discrimination, in order to soften the competition via corporate tax rates in the last stage of the game. We will argue that these results may hold quite different implications for the policy initiatives mentioned above, which aim at eliminating specific tax breaks for foreign-based multinationals on the one hand, and at reducing the profit shifting opportunities of MNEs on the other.

The paper is organized as follows. Section 2 describes the basic model. Section 3 analyzes tax rate competition in the last stage of the game. Section 4 describes the choice of organizational form by firms. Section 5 analyzes non-cooperative discrimination policies in the first stage. Section 6 turns to the welfare effects of coordinated changes in discrimination policies. Section 7 discusses our results and Section 8 concludes. 


\section{The model}

We analyze a model where two identical countries compete in capital tax rates and in the tax advantages granted to MNEs, while firms endogenously choose their organizational form. ${ }^{8}$ We consider the following sequence of events. In the first stage, governments decide on the degree of tax discrimination between mobile and immobile firms. In the second stage, capital owners decide on whether to invest a lump sum in order to become a mobile, multinational firm, or remain an immobile, domestic firm. In the third stage, governments choose statutory capital tax rates. Finally, mobile firms decide where to produce and production and consumption plans are realized. All agents perfectly anticipate future decisions and the model is solved by backward induction. Hence the description in this and the following section treats the decision of firms to be mobile or immobile as exogenous, and derives the sub-game perfect solution for the non-cooperative choice of tax rates.

Consider then two identical countries $i \in\{1,2\}$, which form a federation. The (representative) resident of each of countries 1 and 2 owns $e$ units of capital. The capital invested and employed in country $i$ is denoted $k_{i}$. Internationally mobile and immobile capital are perfect substitutes in the production of output. Full employment of the fixed aggregate supply of capital implies

$$
k_{1}+k_{2}=2 e
$$

The production function $f\left(k_{i}\right)$ exhibits the usual properties $f^{\prime}\left(k_{i}\right)>0, f^{\prime \prime}\left(k_{i}\right)<0$. Each country's capital endowment is divided between $h_{i}$ units of immobile capital and $\bar{m}_{i}$ units of mobile capital, where $h_{i}$ and $\bar{m}_{i}$ are predetermined at this stage of the game

$$
e=h_{i}+\bar{m}_{i} \quad i \in\{1,2\}
$$

Mobile capital can locate anywhere in the federation costlessly, whereas immobile capital cannot be moved at all. The quantity of mobile capital employed in country $i$ is endogenous, and is denoted $m_{i}$. The total quantity of capital mobile and immobile, in country $i$ is thus

$$
k_{i}=h_{i}+m_{i} \quad \forall \quad i \quad \in\{1,2\} \quad h_{i}, m_{i} \geq 0,
$$

\footnotetext{
${ }^{8}$ Throughout our analysis, the terms capital and firms are used interchangeably.
} 
where equations (1)-(3) imply that $\bar{m}_{1}+\bar{m}_{2}=m_{1}+m_{2}$.

All capital employed in country $i$ is taxed at source, and at the same statutory rate $t_{i}$. However, mobile capital faces a lower effective rate, since it can shelter income. Let $1-\phi_{i}$ be the share of capital income which can be sheltered from tax so that $\phi_{i}$ measures to which extent the two countries enforce taxes on mobile capital. ${ }^{9}$ To keep our model as simple as possible we do not incorporate any costs of this tax sheltering, and hence do not model an optimal tax avoidance decision taken by mobile firms.

With tax sheltering the effective tax rate on mobile capital in country $i$ is

$$
\tau_{i} \equiv \phi_{i} t_{i}, \quad 0 \leq \phi_{i} \leq 1
$$

The gross return to capital in country $i$ is $f^{\prime}\left(k_{i}\right)$. Following a standard simplification, we assume that taxes are imposed per unit of capital so that the net return for a unit of mobile capital is $f^{\prime}\left(k_{i}\right)-\tau_{i}$. If there is some mobile capital employed in each country, then this net return must be equalized between countries. Hence

$$
r=f^{\prime}\left(k_{i}\right)-\tau_{i}=f^{\prime}\left(k_{j}\right)-\tau_{j} \quad \forall \quad i, j, \quad i \neq j,
$$

where $r$ is the endogenous net return to mobile capital in the federation. Together with the capital market clearing condition (1), this determines the allocation of capital as a function of the effective tax rates $\tau_{i}$ in each country. ${ }^{10}$ The response of the capital tax base to a change in each country's effective tax rate is determined by implicitly differentiating (5). This yields the conventional result that the capital tax base in each country is falling in its own tax rate, but rising in the tax rate of the other country:

$$
\frac{\partial k_{i}}{\partial \tau_{i}}=\frac{1}{f^{\prime \prime}\left(k_{i}\right)+f^{\prime \prime}\left(k_{j}\right)}<0, \quad \frac{\partial k_{i}}{\partial \tau_{j}}=-\frac{\partial k_{i}}{\partial \tau_{i}}>0 \quad \forall i, j, i \neq j .
$$

Immobile capital faces the full statutory tax rate. Hence, while mobile and immobile capital receive the same gross return, immobile capital bears a higher tax burden and

\footnotetext{
${ }^{9}$ One possible example of this sort of sheltering is "thin capitalization", whereby the firm borrows money from an affiliate in a tax haven located outside the federation. Here $1-\phi_{i}$ would indicate the fraction of its capital costs which can be deducted in country $i$. See Mintz and Smart (2004).

${ }^{10}$ Notice that, if each country employs some of the mobile factor, the allocation of capital across countries, and the net return to mobile capital, can both be expressed solely as a function of the effective tax rates and the total stock of capital. They do not depend directly on the tax shifting parameter, nor on the division of capital between mobile and immobile.
} 
receives a lower net return:

$$
r_{i}^{h}=f^{\prime}\left(k_{i}\right)-t_{i}=r-\frac{1-\phi_{i}}{\phi_{i}} \tau_{i} \quad \forall i
$$

In the following, it proves convenient to define a measure for the degree of tax discrimination in favour of mobile capital. This measure is

$$
\rho_{i} \equiv \frac{1-\phi_{i}}{\phi_{i}}, \quad \infty>\rho_{i} \geq 0
$$

If taxes on mobile capital are fully enforced $\left(\phi_{i}=1\right)$ there is no discrimination and $\rho_{i}=0$. In contrast, in the absence of any enforcement of taxes on mobile capital $\left(\phi_{i} \rightarrow 0\right)$, the tax preference for MNEs becomes arbitrarily large and $\rho_{i} \rightarrow \infty$. From the definition of $\rho_{i}$ and (7) the tax advantage of a unit of mobile capital over a unit of immobile capital is given by $t_{i}-\tau_{i}=\rho_{i} \tau_{i}$.

As immobile capital will be taxed more heavily, its taxation may reach an upper bound. An obvious constraint is that the net return to immobile capital must be non-negative. Since $k_{i}=e$ in any symmetric equilibrium, this constraint implies an exogenous ceiling for the statutory tax rate equal to $\bar{t}=f^{\prime}(e)$. This ceiling will in turn constrain the effective tax rate on mobile capital, if the discrimination parameter $\rho_{i}$ is sufficiently large. From (4) and (8) the maximum effective tax rate $\tau^{M}$ is

$$
\tau^{M} \equiv \frac{\bar{t}}{1+\rho_{i}} \equiv \frac{f^{\prime}(e)}{1+\rho_{i}} \quad \forall \quad i
$$

There is a representative individual in each jurisdiction, who owns the region's capital endowment and receives residual labour income $f\left(k_{i}\right)-f^{\prime}(.) k_{i}$, which remains untaxed. Using (5) and (7), private consumption of the representative individual is

$$
x_{i}=f\left(k_{i}\right)-f^{\prime}(.) k_{i}+e r-\rho_{i} \tau_{i} h_{i} \quad \forall \quad i,
$$

whereas the total tax revenue collected by the source-based capital tax is

$$
g_{i}=\tau_{i}\left(k_{i}+\rho_{i} h_{i}\right) \quad \forall \quad i .
$$

The government maximizes the utility function of the representative agent, given by

$$
u_{i}=x_{i}+(1+\varepsilon) g_{i}=f\left(k_{i}\right)+\left(e-k_{i}\right) r+\varepsilon \tau_{i}\left(k_{i}+\rho_{i} h_{i}\right) \quad \forall \quad i,
$$


where (5), (10) and (11) have been used in the second step. The utility function (12) exhibits a constant marginal rate of substitution between the public and the private good, where $1+\varepsilon$ is the marginal cost of public funds and $\varepsilon$ represents the exogenous excess burden of the tax system. ${ }^{11}$ For any $\varepsilon>0$, countries would like to coordinate on high effective tax rates on capital, since this provides a non-distortionary source of funding for the public sector.

\section{Last stage: Tax rates}

In the final stage of the game, governments choose their capital tax rates. Since the discrimination parameter $\rho_{i}$ is already fixed at this stage, it does not matter whether the statutory tax rate or the effective tax rate is considered as choice variable: equation (4) shows the relation between $t_{i}$ and $\tau_{i}$ for any given level of $\phi_{i}$. In the following it will prove more convenient to treat the effective tax rates $\tau_{i}$ as strategic variables.

Substituting (10) and (11) in (12) and differentiating with respect to $\tau_{i}$ gives each country's optimal effective tax rate

$$
\varepsilon\left(k_{i}+\rho_{i} h_{i}\right)+(1+\varepsilon) \tau_{i} \frac{\partial k_{i}}{\partial \tau_{i}}+\left(e-k_{i}\right) \frac{\partial r}{\partial \tau_{i}}=0 \quad \forall \quad i=1,2 .
$$

We assume that each country's maximand (12) is a quasi-concave function of its own effective tax rate ${ }^{12}$ as long as $h_{i}<k_{i}$, so that the solution to (13) defines country $i$ 's best response to the tax rate chosen by country $j$. We also assume here that the countries choose identical discrimination parameters $\rho_{i}$ in the first stage of the game. Given this symmetry, a symmetric equilibrium in which $\tau_{1}=\tau_{2}$ is of particular interest.

The best response function implicitly defined by (13) shows how tax preferences to multinationals can alter the incentives to cut taxes. The first term measures the marginal benefit of raising the effective tax rate. These gains include the additional tax

\footnotetext{
${ }^{11}$ The assumption of an exogenous excess burden $\varepsilon$ implies that other distortionary taxes raise the bulk of each country's revenue. This is supported by the empirical observation that corporate income tax revenue has accounted for less than $10 \%$ of total tax revenues (including social security contributions) in the OECD average during the last decades (OECD, 2005).

${ }^{12}$ This will be the case if the production function is quadratic. However, as is well-known in the tax competition literature, it is difficult to find weaker restrictions on the primitives of the model which ensure that this assumption holds.
} 
revenues collected from immobile domestic capital, as measured by the term $\rho_{i} h_{i}$. The second term describes the marginal loss from an increase in $\tau$, which results from a reduction in the capital tax base. Finally, the last term represents an intertemporal terms of trade effect, which disappears in a symmetric equilibrium where $k_{i}=e$.

The effective tax pair $\tau_{1}=\tau_{2}=\tau^{I}$ will be a symmetric interior Nash equilibrium if $\tau_{i}=\tau^{I}$ is a best response of country $i$ to $\tau_{j}=\tau^{I}$. Equation (13) implies that there is at most one symmetric Nash equilibrium tax rate, given by ${ }^{13}$

$$
\tau^{I}=\frac{\varepsilon}{1+\varepsilon}\left[-2 f^{\prime \prime}(e)\right](e+\rho h)
$$

Note that $\tau^{I}$ is rising in the excess burden parameter $\varepsilon$, and it is positive for any positive value of $\varepsilon$.

To ensure that a symmetric Nash equilibrium exists in Regime I, none of the countries must have an incentive to switch to a high-tax strategy where it fully expropriates the return to immobile capital while allowing all mobile capital to move to the other region. This possibility is analyzed extensively in Janeba and Peters (1999), in a model where any tax differential induces all the mobile capital to move to the lower-tax jurisdiction. We assume that countries will not find it optimal to choose this strategy, of letting all the mobile capital locate elsewhere. This will be the case if the amount of mobile capital is not too low, and if the marginal cost of public funds is not too high. Appendix 1 provides the details.

Recall, however, that there is an upper bound on $\tau$ given by (9), which will bind for sufficiently high levels of $\rho$. Therefore, there will be an interior symmetric Nash equilibrium at $\tau_{1}=\tau_{2}=\tau^{I}$ if and only if $\tau^{I}<\tau^{M}$. Otherwise, there will be a corner solution with $\tau_{1}=\tau_{2}=\tau^{M}$.

In the following we will refer to the interior Nash equilibrium with $\tau_{1}=\tau_{2}=\tau^{I}$ as Regime I, and to the corner Nash equilibrium with $\tau_{1}=\tau_{2}=\tau^{M}$ as Regime II. If incentives to compete in tax rates were extremely low, the Nash equilibrium would be in Regime II for any value of $\rho$. This does not seem a very realistic possibility. To ensure that an interior Nash equilibrium exists for some levels of $\rho_{i}$, it must be true

\footnotetext{
${ }^{13}$ Without any further assumptions, it can be shown that the second-order conditions for optimality are satisfied in both countries when $\tau_{1}=\tau_{2}=\tau^{I}$. This result, proved by Bayindir-Upmann and Ziad (2005), implies that $\tau_{1}=\tau_{2}=\tau^{I}$ must be a second-order locally consistent equilibrium.
} 
that $\tau^{I}<\tau^{M}$ when $\rho=0$. From the definition of $\tau^{M}$ in (9) and equation (14) this condition is

$$
\frac{\varepsilon}{1+\varepsilon} \frac{-f^{\prime \prime}(e) e}{f^{\prime}(e)} \leq \frac{1}{2}
$$

Condition (15) implies that neither the excess burden of the tax system nor the elasticity of the marginal product of capital $-f^{\prime \prime}(e) e / f^{\prime}(e)$ are too large. In what follows we assume that this condition is indeed met. ${ }^{14}$ Equilibrium to this tax-setting stage can then be summarized by

Proposition 1 There exists a unique symmetric Nash equilibrium to the tax setting sub-game, in which

$$
\tau_{1}^{*}=\tau_{2}^{*}=\min \left\{\tau^{I} \equiv \frac{\varepsilon}{(1+\varepsilon)}\left[-2 f^{\prime \prime}(e)\right](e+\rho h), \tau^{M} \equiv \frac{f^{\prime}(e)}{(1+\rho)}\right\} .
$$

Either there is an interior Nash equilibrium with $\tau^{*}=\tau^{I}$ (Regime I), or a corner Nash equilibrium with $\tau^{*}=\tau^{M}$ (Regime $\left.I I\right)$.

In the interior Nash equilibrium of Regime I, implicit differentiation of (13) implies that best response functions are upward-sloping and have a slope less than 1 in the neighbourhood of the equilibrium

$$
0<\frac{\partial \tau_{i}^{I}}{\partial \tau_{j}}<1
$$

Our main interest lies in the response of $\tau_{i}^{I}$ to a change in the discrimination parameter $\rho_{i}$. Equation (14) implies that (holding constant the number of immobile firms $h_{i}$ )

$$
\frac{\partial \tau_{i}^{I}}{\partial \rho_{i}}>0 \quad \forall i
$$

Hence, increasing the tax preference in favour of mobile capital raises the effective tax rate on this base. It implies that when $\rho_{i}$ is raised, the statutory tax rate $t_{i}$ will rise by so much in this final stage that it overcompensates for the effect of the narrower tax base for mobile firms [cf. eq. (4)].

\footnotetext{
${ }^{14} \mathrm{~A}$ similar condition is needed to ensure that the equilibrium in the standard Wilson-ZodrowMieszkowski model does not involve tax rates greater than 100\%. For example, Assumption 3 in Bayindir-Upmann and Ziad (2005) generalizes this condition to a variable cost of public funds, and an arbitrary number of identical countries.
} 
Intuitively, the problem faced by the two countries in this final stage is that they are legally constrained to levy the same statutory tax rate $t_{i}$ on both mobile and immobile capital. As long as the excess burden of taxation is positive, they would like to increase the effective tax rate on immobile capital, since that tax is non-distortionary. However this tax increase will drive mobile capital into the other country. Hence, the greater is the ability to discriminate among firms (the larger is $\rho_{i}$ ), the more attractive is it for each country to raise the effective rate of capital taxation. In other words, comparing a given increase in the effective tax rate $\tau_{i}$ under a low and a high value of the discrimination parameter $\rho_{i}$, the 'costs' in terms of losing capital to the other country are the same, but the gain in tax revenue arising from the extra taxation of immobile firms is larger when $\rho_{i}$ is high [see the first term in eq. (13)]. Hence, increases in $\rho_{i}$ shift up each country's best response function, implying higher equilibrium tax rates in Regime $\mathrm{I}$.

In Regime II both countries impose the maximum effective tax $\tau^{M}=\bar{t} /\left(1+\rho_{i}\right)$, given the pre-determined choice of $\rho_{i}$. Hence, there is no interaction between the effective tax rates in the two countries $\left(\partial \tau_{i}^{M} / \partial \tau_{j}=0\right)$. Furthermore, the relationship between $\rho_{i}$ and $\tau_{i}$ is negative in this regime, as a higher discrimination parameter reinforces the exogenous constraint on the effective tax rate

$$
\frac{\partial \tau_{i}^{M}}{\partial \rho_{i}}=\frac{-\tau_{i}^{M}}{\left(1+\rho_{i}\right)}=\frac{-\bar{t}}{\left(1+\rho_{i}\right)^{2}}<0 .
$$

These comparative static results are summarized in:

Proposition 2 In an interior (corner) Nash equilibrium, the effective tax rate on mobile capital is rising (falling) in the degree of tax discrimination.

The symmetric equilibrium in Regime I arises only when each country chooses the same degree of tax preference $\rho_{i}$. However, we can use the results of this section to consider the effects on tax rates of a unilateral change in one country's $\rho_{i}$ in the preceding stage of the game. Equation (13) can be differentiated implicitly to derive these effects: since each country's reaction function has a slope less than 1 [as stated in (16)], small perturbations do not change the qualitative nature of the equilibrium. 


\section{Second stage: Firms' organizational form}

In the tax setting stage of the game, the distribution of firms between internationally mobile and immobile types is exogenous. We now endogenize the decision of firms to choose their organizational form. This decision is driven by two conflicting considerations. On the one hand mobile capital faces a lower effective tax rate and thus receives a higher net return, as analyzed above. On the other hand, it is well-known from the literature on foreign direct investment that becoming "mobile" involves choosing a multinational organizational structure, which may be costly (see Horstmann and Markusen, 1992; Markusen, 2002). ${ }^{15}$

In our setting we assume that there are fixed costs associated with establishing a presence in a tax haven. These costs, denoted $c$, are firm-specific and distributed continuously in the interval $(\underline{c}, \bar{c})$ with density function $g(c)$. Owners of capital compare these firm-specific fixed costs with the tax advantages of mobility. From (7) and (8), the latter are given by $\rho_{i} \tau_{i}$. Hence there is a critical level of fixed costs $c^{*}$, for which

$$
\rho_{i} \tau_{i}-c^{*}=0
$$

All firms with $c \leq c^{*}$ choose to become mobile multinational firms $\left(m_{i}\right)$, whereas firms with $c>c^{*}$ prefer to stay immobile $\left(h_{i}\right)$ and operate only in the residence country of the capital owner. We assume that $\underline{c}<0$ and $\bar{c}>\bar{t}$. The first of these assumptions reflects the fact that there may be non-tax advantages to a multinational form for some firms, whereas the second assumption postulates that the costs of setting up a subsidiary are sufficiently high for some firms to exceed the maximum possible tax advantage. Together these assumptions imply that there will always be some mobile and some immobile firms, for any set of tax policies chosen by the two governments.

The continued presence of mobile firms, even when there are no tax preferences, is crucial for some of the results below. Elimination of all tax preferences would be a very attractive policy for governments, if this resulted in the complete elimination of multinationals. Then countries would have no incentive to cut taxes below their

\footnotetext{
${ }^{15}$ Janeba (2000) considers a trade-off that has some similarities with the one studied here. In his model, a monopolist invests in excess capacities, spread over two countries, in order to induce tax competition between the two hosts and lower its tax payments in equilibrium.
} 
statutory maximum rates in the subsequent stage: the corporate income tax would be a lump-sum tax on domestic capital. But if some mobile firms remain, even in the absence of tax preferences, then countries will want to attract these firms. In fact, with tax preferences absent, tax rate competition in the final stage will be very similar to the standard model where all capital is interregionally mobile, as a cut in effective tax rates will cause no extra revenue leakage from domestic firms in this case [see the discussion of eq. (13) above].

Note that a rise in $\rho_{i}$ affects the tax advantage to mobile firms through both a direct and an indirect effect. Holding tax rates constant, an increase in $\rho_{i}$ directly increases the benefit to a multinational form. But holding $\rho_{i}$ constant, the induced change in the effective capital tax rate will also affect the benefits of being mobile, and capital owners anticipate this additional (indirect) effect. In Regime I, both the direct and the indirect effect work in the same direction, whereas in Regime II they work in opposite directions. Substituting the equilibrium tax rate in Regime II shows that the tax advantage $\rho_{i} \tau_{i}$ of multinational form equals $\bar{t} \rho_{i} /\left(1+\rho_{i}\right)$, which is an increasing function of $\rho_{i}$. Hence, in both regimes, an increase in $\rho_{i}$ unambiguously reduces the number of immobile domestic firms:

$$
h_{i}=e\left[1-\int_{\underline{c}}^{\rho_{i} \tau_{i}} g(c) d c\right]=h_{i}\left[\rho_{i}, \tau_{i}\left(\rho_{i}\right)\right] ; \quad \frac{d h_{i}}{d \rho_{i}}<0 .
$$

\section{$5 \quad$ First stage: Discrimination policies}

We now set up each government's problem of choosing the optimal non-cooperative discrimination policy $\rho_{i}$. In this initial stage of the game, the private consumption term in the utility function (12) must account for the aggregate costs that firms pay in equilibrium in order to become multinationals. ${ }^{16}$ The government objective is then

$$
u_{i}=f\left(k_{i}\right)-f^{\prime}(.) k_{i}+e_{i} r-\tau_{i} \rho_{i} h_{i}-\int_{\underline{c}}^{c^{*}} c g(c) d c+(1+\varepsilon) \tau_{i}\left(k_{i}+\rho_{i} h_{i}\right) .
$$

We differentiate with respect to $\rho_{i}$ and employ symmetry and the arbitrage condition (19) for the last mobile firm. Noting that $k_{i}\left[\tau_{i}, \tau_{j}\left(\tau_{i}\right)\right]$ and accounting for the

\footnotetext{
${ }^{16}$ These costs are treated as a pure waste of resources in the present model, because tax savings are the only reason for choosing a multinational structure. In Section 7 we discuss the implications for our results when these costs do not enter the government's optimization problem.
} 
induced change in $\tau_{i}$ in the final stage of the game gives

$$
\begin{aligned}
\frac{\partial u_{i}}{\partial \rho_{i}} & =\left[\varepsilon\left(k_{i}+\rho_{i} h_{i}\right)+(1+\varepsilon) \tau_{i} \frac{\partial k_{i}}{\partial \tau_{i}}\right] \frac{d \tau_{i}}{d \rho_{i}}+(1+\varepsilon) \tau_{i} \frac{\partial k_{i}}{\partial \tau_{j}} \frac{\partial \tau_{j}}{\partial \tau_{i}} \frac{d \tau_{i}}{d \rho_{i}} \\
& +\tau_{i}\left[\varepsilon h_{i}+(1+\varepsilon) \rho_{i} \frac{d h_{i}}{d \rho_{i}}\right]=0 .
\end{aligned}
$$

Equation (22) is valid for both regimes discussed above. Note first that, when deciding upon the level of $\rho_{i}$ in the first stage of the game, each government will take account of both the direct effect and the indirect effect (via the induced change in $h_{i}$ ) that this will have on the optimal effective tax rate $\tau_{i}$ in the final stage. In Regime I, we get from differentiation of (14)

$$
\left.\frac{d \tau_{i}}{d \rho_{i}}\right|^{I}=\frac{\partial \tau_{i}}{\partial \rho_{i}}+\frac{\partial \tau_{i}}{\partial h_{i}} \frac{d h_{i}}{d \rho_{i}}=\frac{\varepsilon}{1+\varepsilon}\left(-2 f^{\prime \prime}\right) h\left(1-\mu_{i}\right)>0 .
$$

Here we have defined

$$
\mu_{i} \equiv-\frac{d h_{i}}{d \rho_{i}} \frac{\rho_{i}}{h_{i}}>0
$$

as the absolute value of the elasticity with which the number of immobile firms responds to tax preferences. Note that this is a total elasticity, taking account of the direct and indirect effects in eq. (20). We argue below that $d \tau_{i} /\left.d \rho_{i}\right|^{I}>0$ must hold in Regime I. In Regime II, only the direct effect matters and $d \tau_{i} /\left.d \rho_{i}\right|^{I I}=\partial \tau_{i}^{M} / \partial \rho_{i}<0$ from (18). We can now discuss the different terms in (22). The first effect is zero in Regime I, where the effective tax rate can be chosen optimally [see eq. (13)], but it is negative in Regime II where $d \tau / d \rho_{i}<0$ and each country is constrained in setting its optimal tax rate $\left(\tau_{i}^{M}<\tau_{i}^{I}\right)$. The second term describes the effect that the choice of $\rho_{i}$ has on the intensity of tax competition in the final stage of the game. This effect must be positive in Regime I. ${ }^{17}$ Each country anticipates that the rise in its own tax rate induced by a higher level of $\rho_{i}$ will cause the other country to also raise its tax [eq. (16)], thus softening tax competition in the final stage of the game. In Regime II, the second term in (22) is zero, because the two tax rates are independent of each other. Finally, the third term incorporates the trade-off that exists for any given level of $\tau_{i}$ between being

\footnotetext{
${ }^{17}$ To see why $d \tau_{i} / d \rho_{i}>0$ must hold in Regime I, note that $d \tau_{i} / d \rho_{i}<0$ would imply $\mu_{i}>1$ from (23). In this case the third term in (22) will also be negative. Since the first term is zero in Regime I, a negative sign of the total effect $d \tau_{i} / d \rho_{i}$ is thus inconsistent with an equilibrium in this regime.
} 
able to tax the immobile firms more heavily (the positive first effect) and reducing the number of immobile firms (the negative second effect). In both regimes, the net effect in the third term is positive, if $\varepsilon /(1+\varepsilon)$ exceeds the elasticity $\mu_{i}$ defined in (24).

We first evaluate the first-order condition (22) at $\rho_{i}=0$. Since condition (15) is assumed to hold, the resulting Nash equilibrium in the final stage must then be in Regime I. Moreover, with $\rho_{i}=0$, both the elasticity $\mu_{i}$ in (23) and the negative second part in the third term are zero so that $\partial u_{i} /\left.\partial \rho_{i}\right|_{\rho=0}>0$ holds unambiguously. This indicates that some tax discrimination between mobile and immobile firms will always be introduced by optimizing governments. Intuitively, introducing a small tax advantage for mobile firms allows to raise the effective tax rate in the final stage of the game, increasing tax revenues. On the other hand, the reduction in $h_{i}$ induced by a rise in $\rho_{i}$ causes no first-order revenue losses when the initial level of tax discrimination is zero.

To analyze the conditions under which an interior Nash equilibrium in Regime I exists in the third stage of the game, we denote by $\tilde{\rho}$ the level of tax discrimination that forms the boundary between the two regimes. Note that equation (22) is not continuous at $\tilde{\rho}_{i}$, because the second term is strictly positive in Regime I (see footnote 17), but zero in Regime II. Hence the derivative $\partial u_{i} / \partial \rho_{i}$ must be evaluated at $\rho=\tilde{\rho}$ from the left (in Regime I) and from the right (in Regime II). Using (6) and (23) and noting that the first term in (22) disappears on both sides of $\tilde{\rho}$ gives

$$
\begin{aligned}
\left.\frac{\partial u_{i}}{\partial \rho_{i}}\right|_{\rho=\tilde{\rho}} ^{I}= & \varepsilon \tau_{i} h_{i}\left(1-\mu_{i}\right) \frac{\partial \tau_{j}}{\partial \tau_{i}}+(1+\varepsilon) \tau_{i} h_{i}\left[\frac{\varepsilon}{1+\varepsilon}-\mu_{i}\right], \\
& \left.\frac{\partial u_{i}}{\partial \rho_{i}}\right|_{\rho=\tilde{\rho}} ^{I I}=(1+\varepsilon) \tau_{i} h_{i}\left[\frac{\varepsilon}{1+\varepsilon}-\mu_{i}\right] .
\end{aligned}
$$

This leads to three possible scenarios. In the first case, $\partial u_{i} /\left.\partial \rho_{i}\right|_{\rho=\tilde{\rho}}<0$ holds when $\tilde{\rho}$ is approached from either side. In this case a discrimination level $\tilde{\rho}$ will be 'too high' from the perspective of national welfare maximization. It then follows from the continuity of $u_{i}$ in $\rho_{i}$ that there must be an optimal discrimination level $\rho_{i}^{*}<\tilde{\rho}_{i}$ that leads to an interior Nash equilibrium in Regime I in the final tax-setting stage. Intuitively, tax preferences are a costly instrument for governments to use in this case, because the decision of firms to become multinationals responds elastically to tax preferences. 
In the second case, the derivatives in (25a)-(25b) are both positive. Hence a further increase in $\rho_{i}$ will be optimal and the tax-setting equilibrium in the final stage will be in Regime II. In this case the number of immobile firms changes only little in response to the tax preferences given to multinationals. Thus, the optimal policy is to choose a high level of $\rho_{i}$ in the first stage of the game, as this allows the country to tax the immobile firms at the maximum statutory rate $\bar{t}$.

Finally, in the third case we have $\partial u_{i} /\left.\partial \rho_{i}\right|_{\rho=\tilde{\rho}} ^{I} \geq 0$, but $\partial u_{i} /\left.\partial \rho_{i}\right|_{\rho=\tilde{\rho}} ^{I I}<0$. In this case, the optimal policy in each country is to set $\rho=\tilde{\rho}$. The results of our analysis in this section are summarized in

Proposition 3 If the elasticity with which firms respond to tax preferences is high (low), relative to the excess burden parameter, so that $\mu \geq \varepsilon /[1+\varepsilon](\mu<\varepsilon /[1+\varepsilon])$ holds at $\rho_{i}=\tilde{\rho}$, then the non-cooperative choice of discrimination policies leads to an interior (corner) Nash equilibrium in the final tax-setting stage.

\section{Coordinating discrimination policies}

The final step in our analysis is to determine whether the non-cooperative choice of discrimination policies is efficient from a global welfare perspective. Suppose then that countries could coordinate, in the first stage, on a common level for the tax discrimination parameter $\rho$, knowing that they will still set effective tax rates non-cooperatively in the third stage. This setting is at the core of current policy debates in both the EU and the OECD, where an international coordination of tax discrimination policies is actively pursued, but countries remain free to set corporate tax rates autonomously.

Starting from a symmetric, non-cooperative equilibrium in either Regime I or Regime II, the joint welfare effects of a marginal, coordinated increase in $\rho$ can be determined solely by evaluating the spillover effects that a small increase in country $i$ 's discrimination policy $\rho_{i}$ has on welfare in country $j(j \neq i)$. The (first-order) effect on country $i$ 's own welfare must be zero from the optimality of the initial equilibrium, and the simultaneous increase in $\rho_{j}$ has identical effects due to the symmetry of the model. Hence, we differentiate $u_{j}$ in equation (21) with respect to $\rho_{i}$ and proceed in a 
way analogous to the derivation of (22). This gives

$$
\frac{\partial u_{j}}{\partial \rho_{i}}=\left[\varepsilon\left(k_{j}+\rho_{j} h_{j}\right)+(1+\varepsilon) \tau_{j} \frac{\partial k_{j}}{\partial \tau_{j}}\right] \frac{\partial \tau_{j}}{\partial \tau_{i}} \frac{d \tau_{i}}{d \rho_{i}}+(1+\varepsilon) \tau_{j}\left[\frac{\partial k_{j}}{\partial \tau_{i}} \frac{d \tau_{i}}{d \rho_{i}}+\rho_{j} \frac{d h_{j}}{d \rho_{i}}\right] \quad \forall i \neq j .
$$

Note that the first of these terms is now zero in both regimes: in Regime I, the term in the squared bracket is zero from (13), whereas $\partial \tau_{j} / \partial \tau_{i}=0$ holds in Regime II. Moreover, in Regime II we also have $d h_{j} / d \rho_{i}=0$, as a change in country $i$ 's discrimination parameter neither has a direct effect nor an indirect effect (because there is no induced change in $\tau_{j}$ ) on firms' choices in country $j$. Therefore, the effects on country $j$ 's welfare in the two regimes are

$$
\begin{gathered}
\left.\frac{\partial u_{j}}{\partial \rho_{i}}\right|^{I}=(1+\varepsilon) \tau_{j}\left(\left.\frac{\partial k_{j}}{\partial \tau_{i}} \frac{d \tau_{i}}{d \rho_{i}}\right|^{I}+\rho_{j} \frac{d h_{j}}{d \rho_{i}}\right) \quad \forall i \neq j, \\
\left.\frac{\partial u_{j}}{\partial \rho_{i}}\right|^{I I}=\left.(1+\varepsilon) \tau_{j} \frac{\partial k_{j}}{\partial \tau_{i}} \frac{d \tau_{i}}{d \rho_{i}}\right|^{I I}<0 \quad \forall i \neq j .
\end{gathered}
$$

In Regime II the spillover effect can be readily signed from (6) and (18). An increase in $\rho_{i}$ will induce a reduction in country $i$ 's effective tax rate in this regime, thus harming country $j$ in the final stage of the game. In Regime I, the corresponding first effect is positive, as $d \tau_{i} / \rho_{i}>0$ must hold in this regime [cf. eq. (23) and footnote 17], and the rise in $\tau_{i}$ allows country $j$ to also raise its tax in the final stage of the game [from eq. (16)]. However, anticipating the tax increase in the final stage, some additional firms in country $j$ will choose a multinational form $\left(d h_{j} / d \rho_{i}<0\right)$ so that the second term in (26a) is negative. Nonetheless it can be shown that the first effect must dominate in this regime, and a small increase in country $i$ 's discrimination policy raises welfare in country $j$. The proof requires a detailed calculation of the comparative static effects of the model and is relegated to Appendix 2. We can then state:

Proposition 4 If the elasticity with which firms change their organizational form is sufficiently high (low), so that an interior (corner) equilibrium results in the final stage, then a small coordinated increase (reduction) in the tax preferences given to mobile firms must be jointly welfare increasing.

Proof: See Appendix 2.

Proposition 4 shows that the implications for welfare-improving changes in coordination policies are exactly opposed in the two regimes that underlie our analysis. In Regime I, 
a higher level of $\rho_{i}$ will lead to less aggressive tax competition (that is, a higher effective tax rate) by country $i$ in the final stage of the game, thus relaxing the constraint for country $j$ 's choice of capital tax rate. In this regime, non-cooperative discrimination policies thus lead to a Nash equilibrium with too few tax advantages granted to internationally mobile firms. In Regime II, in contrast, a coordinated increase in the discrimination parameters aggravates the exogenous constraint on statutory tax rates. This reduces the effective taxation of mobile firms in the final stage of the game, lowering welfare in both countries. In this case the non-cooperative Nash equilibrium in Regime II thus features too many tax advantages granted to multinational firms.

So far our analysis in this section has been confined to small coordinated changes in discrimination policies, starting from a non-cooperative equilibrium. What is the degree of tax discrimination that maximizes joint welfare in our model? Within Regime II, equation (26b) shows that welfare must monotonously decline with the degree of tax preferences. In Regime I our previous analysis has shown that the net effect in (26a) is positive for a small increase in $\rho$ above the non-cooperative level. It is not clear, however, that $\rho$ should be increased all the way to the boundary between the two regimes, given by $\tilde{\rho}$. The reason for this ambiguity is that the benefits of decreased tax competition may be offset by the increases in total fixed costs incurred by firms.

Whether discrimination should be increased or decreased within Regime I is determined by the elasticity of firm structure with respect to the coordinated tax advantage $\rho \tau$ of multinational form. This elasticity is defined by

$$
\eta \equiv-\frac{d h}{d \rho \tau} \frac{\rho \tau}{h}=\frac{g(\rho \tau) \rho \tau}{\int_{\rho \tau}^{\infty} g(c) d c}>0,
$$

where the second step uses (20). In Appendix 3 we derive a condition for $\eta$ which ensures that coordinated increases $\rho$ are welfare-enhancing throughout Regime I:

Proposition 5 The optimal coordinated discrimination policy cannot exceed $\tilde{\rho}$. If $\eta \leq$ $\varepsilon /(1+\varepsilon)$, then the optimal coordinated discrimination policy equals $\tilde{\rho}$, and maximizes the effective tax rate set in the last stage of the game.

Proof: See Appendix 3.

Hence, if $\eta$ is sufficiently low, then the gain in tax revenues resulting from a joint increase in $\rho$ dominates the induced increase in firms' fixed costs throughout Regime I. 
In this case countries will jointly choose the discrimination policy that induces each one of them to levy the highest possible level of $\tau$ in the non-cooperative final stage of the game. But this level is reached just at the boundary between the two regimes, as $\tau$ is rising in $\rho$ in Regime I, but falling in $\rho$ in Regime II.

Finally, note the similarity between Proposition 5 and our earlier result on optimal non-cooperative discrimination policies in Proposition 3. In both cases the valuation of public goods, $\varepsilon /(1+\varepsilon)$, acts as a critical threshold which determines whether either a unilateral increase in discrimination policies (implying a comparison with the elasticity $\mu_{i}$ ) or a coordinated increase in $\rho$ (implying a comparison with $\eta$ ) are welfare-enhancing. It is shown in Lemma 1 of Appendix 2 that $\eta<\mu_{i}$ must hold in the relevant case where both elasticities are below unity. Hence there is a positive parameter range $\eta<\varepsilon /(1+\varepsilon)<\mu_{i}$ where the uncoordinated equilibrium is in Regime I, but the coordinated optimum requires $\rho=\tilde{\rho}$, on the boundary between regimes.

\section{Discussion}

At a basic level, the distinction between two regimes in our model incorporates in a single framework the two benchmark cases that have been introduced in previous work on corporate tax discrimination. Janeba and Peters (1999) distinguish exogenously between a tax base that is costlessly mobile internationally and an immobile domestic tax base in each country. This setting corresponds to our model in the special case where the elasticity with which firms adjust their organizational form is zero. Corresponding to the results of Janeba and Peters, this case is associated in our analysis with maximum taxation of the immobile factor in the final stage (Regime II, see Proposition 3) and excessive tax preferences granted to MNEs (Proposition 4). In contrast, Keen (2001) assumes that both tax bases are internationally mobile to some degree. In this setting, coordinated restrictions on tax preferences are globally welfare-reducing, as they will make tax competition more aggressive. While the set-up of our model is different, its implications are similar to Keen's when an interior Nash equilibrium in taxes occurs in the final stage (Regime I). Moreover, due to the sequential nature of decisions in our model, the positive relationship between the tax discrimination parameter and the effective tax rate is explicitly incorporated as a comparative static effect [eq. (17)]. 
There is, however, an important difference between our work and that of both Janeba and Peters (1999) and Keen (2001). In the two latter analyses, the trade-off for tax policy arises at the tax-setting stage: the constraint to impose equal tax rates on both bases (the elimination of tax preferences for the more mobile base) increases the equilibrium tax on the mobile base, relative to the unconstrained case, but simultaneously lowers the tax rate on the less mobile base. As shown by Janeba and Smart (2003), the net effect on tax revenues then depends on the elasticity of each tax base with respect to a single country's tax rate on the one hand, and with respect to a coordinated tax change on the other. In the present model, in contrast, an increase in the tax preferences granted to mobile firms increases, in a Regime I equilibrium, the effective tax rate levied on the immobile and on the mobile tax base. Hence, there is no trade-off for tax policy at this stage. However, the mix between the mobile and the immobile tax base changes in our analysis, whereas this is held fixed in previous work. Hence the elasticity with which firms change their organizational form in response to tax incentives is the single core parameter in our model, which determines the nature of the equilibrium.

How is the critical value for this elasticity affected by the assumptions of the model? A first modification considers the case where the firms' costs of investing in a subsidiary are not treated as a pure waste, for example because the multinational structure simultaneously saves on transportation or factor costs. This change affects the last term in the first-order condition for the choice of discrimination policy [eq. (22)], as the costs of a change in the number of immobile firms are weighed only by $\varepsilon$ (instead of $1+\varepsilon$ ). Evaluating at $\rho=\tilde{\rho}$ from the right (in Regime II), equation (25b) then changes to

$$
\left.\frac{\partial u_{i}}{\partial \rho_{i}}\right|_{\rho=\tilde{\rho}} ^{I I}=\varepsilon \tau_{i} h_{i}\left(1-\mu_{i}\right) .
$$

All qualitative results remain unchanged in this case, but the condition for a corner tax equilibrium (Regime II) to occur in the final stage is now $\mu_{i}<1$. Since this condition is weaker than in the main part of the analysis (where $\mu_{i}<\varepsilon /[1+\varepsilon]$ ), it becomes more likely that high tax preferences are given to multinational firms in the first stage, and the taxation of immobile firms in the last stage reaches the upper bound. ${ }^{18}$ The reasons for this change are obvious: the 'costs' of a discriminatory tax

\footnotetext{
${ }^{18}$ The same result is obtained when countries care only about tax revenues. Under this assumption the valuation of public goods is infinitely high, relative to private consumption $[\varepsilon /(1+\varepsilon) \rightarrow 1]$.
} 
policy are reduced, as each government now considers only the loss in tax revenue when firms choose a multinational structure.

Moreover, we have assumed throughout our analysis that countries can commit to a long-term discrimination policy. Consider now the effects when countries can adjust their discrimination policy after firms have decided on their organizational structure. There are several possible sequences of events if countries' power to commit to tax preferences is weak. Suppose first that they are still able to coordinate on tax preferences, so that first firms choose their organizational structure, then countries coordinate on tax preferences, and then they choose tax rates non-cooperatively. With organizational form fixed, (26a)-(26b) imply that countries' joint payoff is increasing in $\rho$ throughout Regime I, and decreasing in $\rho$ throughout Regime II. Thus they will always choose to set $\rho=\tilde{\rho}$ in coordinating their discrimination policies. If $\eta<\varepsilon /(1+\varepsilon)$ this is the same outcome as would occur if they moved first: commitment carries no advantage. But if the elasticity $\eta$ is sufficiently high, countries will do better if they can commit.

If commitment power was weaker yet, countries might not even be able to coordinate on $\rho$. In this situation, firms would move first, and then countries would choose their tax rates and tax preferences simultaneously and non-cooperatively. Choosing $\rho_{i}$ and $t_{i}$ simultaneously effectively decouples the taxation of mobile and immobile firms. Each country would tax immobile firms at the highest rate possible, and compete for mobile firms as in the standard tax competition model. This equilibrium would necessarily be in Regime II in our model. Hence, the outcome will be unambiguously worse than if countries can coordinate on a common level of tax preferences, $\tilde{\rho}$, prior to firms' choice of organizational form.

Note, finally, that a first-best equilibrium, where all taxes are lump-sum, is not feasible in our model, even when countries can cooperatively determine whether to grant any tax relief to mobile firms. This is ensured by the assumption of a negative lower bound on the firm-specific fixed costs of becoming a multinational $(\underline{c}<0)$. This assumption implies that there will always be some mobile firms, even if there are no tax advantages to being mobile. This model element incorporates the obvious fact that there are multiple reasons for choosing a multinational structure, and tax savings are only one of them. An alternative assumption that yields the same qualitative results would have been to introduce convex costs to the government of preventing tax shifting by 
multinational firms (Kant, 1988). In this case, it is too costly for each government to prevent profit shifting completely, giving firms with positive, yet small, fixed costs an incentive to choose the mobile type in equilibrium. Hence, in this alternative scenario, tax competition will again take place in the final stage of the game.

\section{Conclusions}

This paper has analyzed a sequential game between two symmetric countries when firms can invest in a multinational structure that confers tax savings and governments are able to commit to long-run tax discrimination policies. The fundamental tradeoff for governments in this setting is that granting tax breaks to MNEs softens tax rate competition in the final stage of the game, but a preferential tax policy also provides incentives for firms to choose a multinational structure with the sole purpose of benefitting from tax breaks. The non-cooperative equilibrium in tax discrimination strategies and corporate tax rates can be in one of two regimes. If the firms' choice of organizational structure is rather insensitive to tax preferences, then countries will choose a high degree of tax discrimination in the first stage, and maximum taxation of immobile firms in the last. If, however, the firms' organizational structure responds elastically to tax preferences, then countries will choose moderate tax preferences for mobile firms in the first stage and interior levels of tax rates in the last.

These results offer one possible reason why tax breaks for multinational firms are limited in practice, despite the high mobility of this tax base. In setting their discrimination policy, governments take into account the incentives given to firms to invest in a multinational structure, in order to reduce tax payments in subsequent periods. At the same time our discussion has pointed out the advantages to governments of committing to (empirically observed) long-run policies with respect to both profit-shifting rules and discrete tax breaks for multinationals firms. This policy avoids what can be termed a reverse hold-up problem: if tax discrimination were perceived by firms to change in the short run, there would be an incentive for them to overinvest in a multinational structure, in order to pressure governments to grant additional tax breaks.

Our analysis can be applied to the recent policy moves in both the European Union and the OECD, which aim at reducing the tax preferences in favour of multinational firms, 
but leave national governments full autonomy over capital tax rates. Our results suggest that these coordination measures may have rather different effects. The EU's Code of Conduct (European Communities, 1998) and the OECD's (1998) guidelines against 'harmful tax practices' address practices in which individual countries try to 'ring-fence' their domestic tax bases by tailoring tax breaks to foreign-based firms without granting domestic firms (even domestic multinationals) the same benefits. Hence, countries need not fear that domestic firms respond to tax preferences by changing their organizational form. In this setting the 'costs' of granting generous tax preferences are thus small, and the non-cooperative equilibrium is likely characterized by strong tax preferences for multinational firms. Hence, according to our model, a coordinated reduction in these tax preferences is indeed likely to raise revenues and welfare in each country.

In contrast, tax advantages conferred to MNEs via transfer pricing opportunities are a costly instrument from the perspective of national governments, as they give domestic firms an incentive to change their organizational form. When this response is sufficiently elastic, the non-cooperative equilibrium will feature only moderate tax advantages through transfer pricing. Coordinated efforts to reduce these tax shifting opportunities, such as the current proposal to tax multinationals on the basis of an allocation formula (European Commission, 2001) then have the potential to render tax rate competition more aggressive, and hence be welfare-reducing.

Our analysis has emphasized the incentives that long-term tax savings give to firms in choosing their organizational form. This choice has become a standard one in the new trade theory, but it has so far been almost completely neglected in the literature on international taxation. Moreover, we are aware of only one empirical study which explicitly analyzes the effect of taxes on the fundamental decision to become a multinational firm, rather than export from the home base (Devereux and Griffith, 1998). While this study does not find a significant impact of taxes on this decision margin, it also does not incorporate special tax preferences of the type analyzed here. Clearly, more theoretical and empirical work would be justified to answer the basic issue of how much taxes contribute to the fundamental decision of firms to choose a multinational structure. 


\section{References}

Bartelsman, E. and R. Beetsma (2003), Why pay more? Corporate tax avoidance through transfer pricing in OECD countries. Journal of Public Economics 8\%, 2225-2252.

Bayindir-Upmann, T., and A. Ziad (2005), Existence of equilibria in a basic taxcompetition model. Regional Science and Urban Economics 35, 1-22

Chirinko, R., S. Fazzari, and A. Meyer (1999), How responsive is business capital formation to its user cost? An exploration with micro data. Journal of Public Economics 74, 53-80

Clausing, K. (2003), Tax-motivated transfer pricing and US intrafirm trade prices. Journal of Public Economics 87, 2207-2223

Cremer, H. and F. Gahvari (2000), Tax evasion, fiscal competition and economic integration. European Economic Review 44, 1633-1657.

Devereux, M.P. and R. Griffith (1998), Taxes and the location of production: Evidence from a panel of US multinationals. Journal of Public Economics 68, 335-367.

European Commission (2001), Towards an internal market without tax obstacles. A strategy for providing companies with a consolidated corporate tax base for their EU-wide activities. Document COM(2001) 582, Brussels.

European Communities (1998), Conclusions of the ECOFIN Council meeting on 1 December 1997 concerning taxation policy (including code of conduct for business taxation). Official Journal of the European Communities 98/C 2/01, Brussels.

Gérard, M. (2005) Multijurisdictional firms and governments' strategies under alternative tax designs. CESifo Working Paper 152\%. Munich.

Gresik, T. (2001), The taxing task of taxing transnationals. Journal of Economic Literature 39, 800-838.

Haupt, A. and W. Peters (2005), Restricting preferential tax regimes to avoid harmful tax competition. Regional Science and Urban Economics 35, 493-507. 
Hines, J.R. (1999), Lessons from behavioral responses to international taxation. $\mathrm{Na}$ tional Tax Journal 52, 304-322

Hong, Q. and M. Smart (2005), In praise of tax havens: International tax planning and foreign direct investment. Unpublished manuscript, University of Toronto.

Horstmann, I. and J. Markusen (1992), Endogenous market structures in international trade (natura facit saltum). Journal of International Economics 32, 109-129.

Janeba, E. (2000), Tax competition when governments lack commitment: Excess capacity as a countervailing threat. American Economic Review 90, 1508-1519.

Janeba, E. and W. Peters (1999), Tax evasion, tax competition and the gains from nondiscrimination: The case of interest taxation in Europe. The Economic Journal 109, 93-101.

Janeba, E. and M. Smart (2003), Is targeted tax competition less harmful than its remedies? International Tax and Public Finance 10, 259-280.

Kant, C. (1988), Endogenous transfer pricing and the effects of uncertain regulation. Journal of International Economics 24, 147-157.

Keen, M. (2001), Preferential regimes can make tax competition less harmful. National Tax Journal 54, 757-762.

Markusen, J.R. (2002), Multinational firms and the theory of international trade. MIT Press.

Mintz, J. and M. Smart (2004), Income shifting, investment, and tax competition: theory and evidence from provincial taxation in Canada. Journal of Public Economics 88, 1149-1168.

OECD (1998), Harmful tax competition: An emerging global issue. Paris.

OECD (2005), Revenue Statistics 1965-2004. www.sourceoecd.org

Peralta, S., X. Wauthy and T. van Ypersele (2003), Should countries control international profit shifting? CORE Discussion Paper 2003/72, Louvain. 
Primarolo Report (1999), Report from the Code of Conduct Group to the ECOFIN Council, 29 November 1999.

Swenson, D. (2001), Tax reforms and evidence of transfer pricing. National Tax Journal 54, 7-25.

Wall Street Journal (2005), Irish subsidiary lets Microsoft slash taxes in U.S. and Europe. November 7, 2005.

Weichenrieder, A. (1996), Fighting international tax avoidance: The case of Germany. Fiscal Studies 17, 37- 58. 


\section{Appendix 1 : Avoiding Discrete Jumps in Tax Rates}

Suppose that country 2 chooses the effective tax rate $\tau^{I}<f^{\prime}(e) /(1+\rho)$. As country 1 increases $\tau_{1}$ above $\tau^{I}$, it will lose mobile capital. The assumption that the country's payoff function is quasi-concave (when $h_{i}<k_{i}$ ) implies that country 1's payoff decreases as it increases $\tau_{1}$ further, if $\tau_{1}$ is already greater than its best response to $\tau_{2}=\tau^{I}$.

However, if $\tau_{1}$ gets high enough, all mobile capital may move to country 2 . This will be the case, at a tax rate $\tau_{1}$ less than the maximum possible rate $\bar{t} /(1+\rho)$, if the following condition holds

$$
f^{\prime}(2 e-h)-\tau^{I}>f^{\prime}(h)-\frac{f^{\prime}(e)}{1+\rho} .
$$

If (A.1) holds, then there is some $\tau^{0} \in\left[\tau^{I}, f^{\prime}(e) /(1+\rho)\right]$ such that $h_{1}=k_{1}$ at $\tau_{1}=\tau^{0}$. In this case further increases in $\tau_{1}$ above $\tau^{0}$ have no impact on $k_{1}$, as $k_{1}=h_{1}$. Raising $\tau_{1}$ above $\tau^{0}$ must then increase the payoff to country 1 , as aggregate income of its residents is unchanged, but more income will be diverted to the public sector.

Therefore, country 1's optimal policy, given that the other country has set an effective tax rate of $\tau^{I}$, is either to choose its interior best response $\tau_{1}=\tau^{I}$, or to choose the maximal possible effective tax rate $f^{\prime}(e) /(1+\rho)$, and lose all mobile capital. The payoff to the first policy is

$$
f(e)+\varepsilon \tau^{I}(e+\rho h)
$$

and the payoff from the second policy is

$$
f(h)+\varepsilon f^{\prime}(e) h+\left[f^{\prime}(2 e-h)-\tau^{I}\right](e-h)
$$

Thus, given that (A.1) holds, the country will wish to 'deviate' by specializing in immobile capital only if

$$
\Delta \equiv \varepsilon\left[f^{\prime}(e) h-\tau^{I}(e+\rho h)\right]-[f(e)-f(h)]+\left[f^{\prime}(2 e-h)-\tau^{I}\right](e-h)>0 .
$$

If there were no firms with negative fixed costs of multinational form, so that $h$ equalled 0 for very low values of $\rho$, then condition (A.4) would have to hold when $h=e$. But our assumption on the cost of multinational form ensures that $h$ is bounded below $e$, for all values of $\rho$. 
Concavity of the production function $f(\cdot)$ implies that $f^{\prime}(2 e-h)<f^{\prime}(e)$, so that $\Delta$ is bounded above by

$$
\varepsilon\left[f^{\prime}(e) h-\tau^{I}(e+\rho h)\right]-[f(e)-f(h)]+\left[f^{\prime}(e)-\tau^{I}\right](e-h)>0 .
$$

From concavity we also have that $f(e)-f(h)>f^{\prime}(e)(e-h)$, implying

$$
\Delta<\varepsilon f^{\prime}(e) h-\tau^{I}[(1+\varepsilon) e-h]
$$

From equation (14)

$$
\tau^{I} \geq \frac{2 \varepsilon}{1+\varepsilon} \frac{f^{\prime}(e)}{\sigma}
$$

where $\sigma$ is the elasticity of capital supply with respect to its net return

$$
\sigma \equiv-\frac{f^{\prime}(e)}{f^{\prime \prime}(e) e}
$$

Equation (A.6) then implies that a sufficient condition for $\Delta$ to be negative is that

$$
\varepsilon h<\frac{2}{\sigma} \frac{\varepsilon}{(1+\varepsilon)}[(1+\varepsilon) e-h]
$$

This condition is equivalent to

$$
\frac{h}{e}<\frac{2(1+\varepsilon)}{(1+\varepsilon) \sigma+2}
$$

Condition (A.7) is a sufficient condition (but not a necessary one) for $\tau_{1}=\tau_{2}=\tau^{I}$ to be a Nash equilibrium to the tax-setting stage when $\tau^{I}<\tau^{M}$ : it implies that a deviation by either country to a maximal statutory tax rate would reduce its payoff. The condition must hold if $\varepsilon$ is sufficiently large, or $\sigma$ sufficiently small. ${ }^{19}$

Condition (A.7) implies fairly weak restrictions on the parameters. For example, Chirinko et al (1999) estimate a value of about 0.25 for the elasticity $\sigma$. If this is the case, as long as at least 12 percent of capital were mobile, then condition (A.7) would have to hold for any positive value of for $\varepsilon$.

\footnotetext{
${ }^{19}$ Whenever $\sigma(1+\varepsilon) / \varepsilon<2$, the right side of condition (A.7) must exceed 1. This implies $\tau^{I}>\tau^{M}$, so that the tax-setting equilibrium must be in Regime II.
} 


\section{Appendix 2: Proof of Proposition 4}

If $\rho_{1}=\rho_{2}$ initially, and if the symmetric third-stage tax-setting equilibrium is in Regime I, then the equilibrium values of $\tau_{1}, \tau_{2}, h_{1}$ and $h_{2}$ can be defined as the solution to the system of four equations

$$
\begin{gathered}
\left(e-k_{i}\right) \frac{\partial r}{\partial \tau_{i}}+\varepsilon\left(k_{i}+\rho_{i} h_{i}\right)+(1+\varepsilon) \tau_{i} \frac{\partial k_{i}}{\partial \tau_{i}}=0 \quad \forall i \in\{1,2\}, \\
h_{i}-\int_{\rho_{i} \tau_{i}}^{\infty} g(c) d c=0 \quad \forall i \in\{1,2\} .
\end{gathered}
$$

A symmetric equilibrium is further characterized by

$$
\frac{\partial k_{i}}{\partial \tau_{i}}=\frac{1}{2 f^{\prime \prime}(e)}, \quad \frac{\partial r}{\partial \tau_{i}}=-\frac{1}{2}, \quad \frac{\partial^{2} k_{i}}{\partial \tau_{i}^{2}}=0 .
$$

Equation (A.8) defines the reaction curve for a country in the final, tax-setting stage. From equation set (A.10), the slope of a reaction curve, in a symmetric equilibrium is

$$
\frac{\partial \tau_{i}}{\partial \tau_{j}}=\frac{1+2 \varepsilon}{3+4 \varepsilon} \quad i \neq j
$$

Also using the results (A.10), the differential of the equation system (A.8)-(A.9) can be written

$$
\left(\begin{array}{cccc}
\frac{3+4 \varepsilon}{4 f^{\prime \prime}(e)} & -\frac{1+2 \varepsilon}{4 f^{\prime \prime}(e)} & \varepsilon \rho & 0 \\
-\frac{1+2 \varepsilon}{4 f^{\prime \prime}(e)} & \frac{3+4 \varepsilon}{4 f^{\prime \prime}(e)} & 0 & \varepsilon \rho \\
\rho g(\rho \tau) & 0 & 1 & 0 \\
0 & \rho g(\rho \tau) & 0 & 1
\end{array}\right)\left(\begin{array}{l}
d \tau_{1} \\
d \tau_{2} \\
d h_{1} \\
d h_{2}
\end{array}\right)=\left(\begin{array}{c}
-\varepsilon h \\
0 \\
-\tau g(\rho \tau) \\
0
\end{array}\right) d \rho_{1}
$$

The determinant of the matrix on the left side of equation (A.12) is

$$
\Delta=A+B
$$

where

$$
\begin{gathered}
A \equiv \frac{(3+4 \varepsilon)^{2}-(1+2 \varepsilon)^{2}}{16\left[f^{\prime \prime}(e)\right]^{2}}-\varepsilon \rho^{2} g(\rho \tau) \frac{3+4 \varepsilon}{4 f^{\prime \prime}(e)}>0, \\
B \equiv \varepsilon^{2} \rho^{4}[g(\rho \tau)]^{2}-\varepsilon \rho^{2} g(\rho \tau) \frac{3+4 \varepsilon}{4 f^{\prime \prime}(e)}>0 .
\end{gathered}
$$

Cramer's Rule then shows the effects on the subsequent stages of a unilateral change in one country's tax preferences

$$
\frac{d h_{i}}{d \rho_{i}}=-\frac{\tau g(\rho \tau) A+(h / \rho) B}{A+B} .
$$


From the definition of the elasticity of firm structure with respect to the tax advantages of MNE form [eq. (27) in the main text] and (A.9)

$$
\eta \equiv-\frac{d h}{d(\rho \tau)} \frac{\rho \tau}{h}=g(\rho \tau) \frac{\rho \tau}{h}
$$

so that equation (A.15) becomes

$$
\frac{d h_{i}}{d \rho_{i}}=-\frac{h}{\rho}\left[1+(\eta-1) \frac{A}{A+B}\right] \quad \Longleftrightarrow \quad 1-\mu_{i}=\frac{A}{A+B}(1-\eta),
$$

where the definition of $\mu_{i}$ in the main text [eq. (24)] has been used. It follows that at a symmetric equilibrium in Regime I:

Lemma 1 If $\eta<1(\eta>1)$ then $\eta<\mu<1(\eta>\mu>1)$.

Further, equation (A.12) implies that

$$
\frac{d h_{j}}{d \rho_{i}}=(1-\eta) \frac{\varepsilon h \rho g(\rho \tau)}{(A+B)} \frac{(1+2 \varepsilon)}{4 f^{\prime \prime}(e)} \quad j \neq i,
$$

so that an increase in one country's tax preferences will decrease the number of immobile firms in the other country if $\eta<1$.

For the response of a country's effective tax rate with respect to its own tax preference parameter, Cramer's Rule gives

$$
\frac{d \tau_{i}}{d \rho_{i}}=(1-\eta) \frac{\varepsilon h}{A+B}\left[\varepsilon \rho^{2} g(\tau \rho)-\frac{3+4 \varepsilon}{4 f^{\prime \prime}(e)}\right],
$$

so that $d \tau_{i} / d \rho_{i}>0$ if and only if $\eta<1$. Moreover, if $\eta<1$, then $d \tau_{j} / d \rho_{i}>0$ also holds from the fact that reaction curves slope up near a symmetric equilibrium.

Moreover, at a symmetric non-cooperative equilibrium, equation (22) can be written

$$
\left.\frac{\partial u_{i}}{\partial \rho_{i}}\right|^{I}=\varepsilon(e+\rho h) \frac{\partial \tau_{j}}{\partial \tau_{i}} \frac{d \tau_{i}}{d \rho_{i}}+\tau_{i}\left[\varepsilon h_{i}+(1+\varepsilon) \rho_{i} \frac{d h_{i}}{d \rho_{i}}\right]=0,
$$

if the third-stage equilibrium is in Regime I. From the definition of $\mu$, and equation (A.11) this becomes

$$
\varepsilon(e+\rho h) \frac{d \tau_{i}}{d \rho_{i}}=-\tau h[\varepsilon-(1+\varepsilon \mu)] \frac{3+4 \varepsilon}{1+2 \varepsilon} .
$$

Using (A.19) and (A.17), and noting that $\varepsilon(e+\rho h)=(1+\varepsilon) \tau_{i}\left(\partial k_{i} / \partial \tau_{i}\right)$ from (13), the spillover effect (26a) in Regime I is

$$
\left.\frac{\partial u_{j}}{\partial \rho_{i}}\right|^{I}=\tau h\left[\frac{3+4 \varepsilon}{1+2 \varepsilon}\right]-\varepsilon(1-\mu) \frac{3+4 \varepsilon}{1+2 \varepsilon}-\frac{(1+\varepsilon) \rho^{2} g(\rho \tau) \varepsilon(1-\eta)(1+2 \varepsilon)}{-4 f^{\prime \prime}(e)(A+B)} .
$$


From the definition (A.13)

$$
\varepsilon \rho^{2} g(\rho \tau) \frac{1+2 \varepsilon}{-4 f^{\prime \prime}(e)}<\frac{A}{2}
$$

so that

$$
\left.\frac{\partial u_{j}}{\partial \rho_{i}}\right|^{I}>\tau h\left[\frac{3+4 \varepsilon}{1+2 \varepsilon}\right]-\varepsilon(1-\mu) \frac{3+4 \varepsilon}{1+2 \varepsilon}-\frac{1}{2}(1+\varepsilon) \frac{A}{A+B} .
$$

This implies that $\partial u_{j} /\left.\partial \rho_{i}\right|^{I}>0$ when

$$
(3+4 \varepsilon)[1-\varepsilon(1-\mu)]-\frac{1}{2}(1+\varepsilon)(1+2 \varepsilon) \frac{A}{A+B}>0 .
$$

The left side of inequality (A.21), viewed as a function of $\varepsilon$ alone (and treating the other parameters as constants) is a concave function. It is also positive when $\varepsilon=0$. Since $\mu \geq \varepsilon /(1+\varepsilon)$ if the non-cooperative equilibrium leads to an outcome in Regime I, the left side of (A.21) must be positive when $\varepsilon=1$. Therefore

Lemma 2 If $0 \leq \varepsilon \leq 1$, then a coordinated increase in the tax preference parameter $\rho$ must increase the payoff to each country, starting from a non-cooperative equilibrium which implies an outcome in Regime I.

Moreover, from equations (26a), (A.17), and (A.18), we have

$$
\left.\frac{\partial u_{j}}{\partial \rho_{i}}\right|^{I}=\frac{(1-\eta) \varepsilon^{2} h(e+\rho h)}{A+B}\left[\varepsilon \rho^{2} g(\rho \tau)+\frac{3+4 \varepsilon}{\left[-4 f^{\prime \prime}(e)\right]}\right]-\frac{(1-\eta)(1+\varepsilon) \rho \eta \varepsilon h^{2}(1+2 \varepsilon)}{(A+B)\left[-4 f^{\prime \prime}(e)\right]}
$$

Since $\eta<1$ at any non-cooperative equilibrium leading to an outcome in Regime I, and since $A$ and $B$ are both positive, this effect will be positive iff

$$
\varepsilon(e+\rho h)\left[\varepsilon \rho^{2} g(\rho \tau)+\frac{3+4 \varepsilon}{\left[-4 f^{\prime \prime}(e)\right]}\right]-\frac{\eta \rho h(1+\varepsilon)(1+2 \varepsilon)}{\left[-4 f^{\prime \prime}(e)\right]}>0 .
$$

But since $e+\rho h>\rho h$, and $3+4 \varepsilon>2(1+2 \varepsilon)$, this will be positive whenever

$$
\eta \leq \frac{2 \varepsilon}{1+\varepsilon} \text {. }
$$

At the non-cooperative equilibrium $\eta<1$. The right side of inequality (A.22) equals 1 when $\varepsilon=1$, and is an increasing function of $\varepsilon$. Therefore

Lemma 3 If $\varepsilon \geq 1$, then a coordinated increase in the tax preference parameter $\rho$ must increase the payoff to each country, starting from a non-cooperative equilibrium which implies an outcome in Regime $I$.

Lemma 2 and Lemma 3 together complete the proof of Proposition 4, if the final-stage equilibrium is in Regime I. 


\section{Appendix 3: Proof of Proposition 5}

Equation (26b) establishes that a reduction in $\rho_{i}$ must increase $u_{j}$ throughout Regime II. In Regime I, consider the effect of a coordinated change in $\rho$. Equations (19) and (14) imply that

$$
h-\int_{\rho C(e+\rho h)}^{\infty} g(c) d c=0
$$

where $C \equiv[\varepsilon /(1+\varepsilon)]\left[-2 f^{\prime \prime}(e)\right]>0$. Differentiation of (A.23) yields

$$
\left.\frac{d h}{d \rho}\right|^{c}=-\frac{h(e+2 \rho h) \eta}{\rho[e+(1+\eta) \rho h]}
$$

where the superscript $c$ is used to denote a simultaneous (coordinated) policy change in both countries. Also, since $\tau=C(e+\rho h)$,

$$
\left.\frac{d \tau}{d \rho}\right|^{c}=C h\left(1+\frac{\rho}{h} \frac{d h}{d \rho}\right)
$$

In a symmetric equilibrium, where each country employs a level of capital $k_{i}=e$, the payoff $u$ to each country's government can thus be written as

$$
u=f(e)-\int_{-\infty}^{\rho \tau} c g(c) d c+\varepsilon \tau(e+\rho h)=f(e)-\int_{-\infty}^{\rho \tau} c g(c) d c+\varepsilon \frac{\tau^{2}}{C} .
$$

Note that a coordinated increase in $\rho$ must increase the number of mobile firms in each country [from equation (A.24)]. Thus a necessary condition for this increase to be welfare-improving is that total tax revenue rises. If $\eta \geq 1$, then equation (A.25) shows that $\tau$, and hence tax revenue falls. Therefore $\eta<1$ is a necessary condition for an increase in $\rho$ to increase utility in each country.

But using (A.25) and (A.26), $d u / d \rho$ can be shown to be proportional to

$$
2 \varepsilon(e+\rho h)-\eta[2 \varepsilon(e+\rho h)+e+2 \rho h]
$$

so that, if $d u / d \rho=0$, then

$$
\frac{\varepsilon}{1+\varepsilon}<\eta<\frac{2 \varepsilon}{1+2 \varepsilon}
$$

holds in Regime I. From this follows that $u$ will be monotonously increasing in $\rho$ throughout Regime I when $\eta<\varepsilon /(1+\varepsilon)$. 